\title{
Infantile Hemangioma Involving Head and Neck Region, Extremities and Internal Organ: A Case Report
}

\author{
Zhao Jianxin* \\ Department of Orthodontics, Japan \\ *Corresponding author: Zhao Jianxin, Department of Orthodontics, Osaka, Japan
}

\begin{tabular}{|c|c|}
\hline ARTICLE INFO & ABSTRACT \\
\hline Received: 崐 January 28, 2019 & Citation: Zhao Jianxin. Infantile Hemangioma Involving Head and Neck Region, Extrem- \\
\hline Published: 慧February 05, 2019 & $\begin{array}{l}\text { ities and Internal Organ: A Case Report. Biomed J Sci \& Tech Res 14(1)-2019. BJSTR. } \\
\text { MS.ID.002497. }\end{array}$ \\
\hline
\end{tabular}

\section{Introduction}

Infantile hemangiomas are benign fibrovascular tumors of infancy that are characterized by a rapid growth phase with endothelial cell proliferation followed by gradual involution. Eighty percent of hemangioma occurs as single lesion. Only $20 \%$ of affected patients will have multiple tumors [1]. They are soft and painless, and often described clinically as a soft tissue mass, smooth or lobulated sessile or pedunculated with variable size. They may be smooth or irregular bulbous in outline [2]. This article describes the case of a 3-month-old boy reported with multiple hemangioma located both in head and neck region and extremities.

\section{Case Report}

A 3-month-old Chinese boy was reported with a history of fever. The ultrasonographic (USG) examination of abdomen and pelvis revealed an ill-defined, hyperechoic lesion in the liver, measuring $3 \times 3 \mathrm{~cm}$. The mother had noticed three tiny red spots distributed in nasal tip, left middle finger and right upper extremity respectively at birth, which rapidly proliferated into masses. Local examination revealed the mass located in right upper arm was the largest in size, up to $5^{*} 4^{*} 3 \mathrm{~cm}^{3}$ approximately. The mass located in nasal tip was $1.5^{*} 1.5^{*} 1.5 \mathrm{~cm}^{3}$ in size, and the third mass surrounded the root part of the left middle finger. All the three masses were pink to red in color, rubbery in consistency, slim surface. Especially, the mass located in upper extremity is crust-covered and no effusion (Figure 1). The cutaneous temperatures of lesions were higher than adjacent normal skin. Palpation revealed the tension of the mass surfaces is quite high and a subcutaneous liquefied layer had generated.
General examination was normal with no deterioration of health status. A provisional diagnosis of multiple infantile hemangioma was made according to their clinical appearances, the growth behaviors and USG. Hematological routine examination revealed all findings to be normal. The patient was treated with 3 courses of low-dose oral prednisone. The dose was $5 \mathrm{mg}$ per kilogram of body weight, q.o.d. and one course of treatment was one month with a slow withdrawal and one following month for gap. After one course of treatment, the size of the three masses shrinked, with the surface of the one located in arm ulcerated then incrusted. In that case the wound was debrided and treated with red LED curing unit. After 3 sessions of debridement and LED treatment (oral prednisone simultaneously), the ulceration started closing and all the three masses softened. Subsequently, USG examination exhibited the minification of the liver lesion to $8 \mathrm{~mm}^{*} 7 \mathrm{~mm}$. Written informed consent for publication of their clinical details and clinical images was obtained from the parents relative of the patient (Figure 2-4).

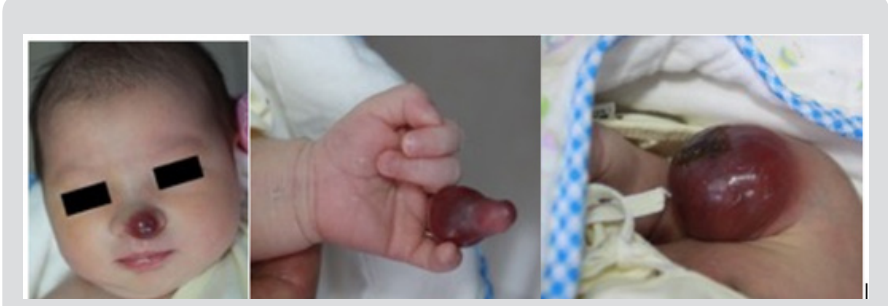

Figure 1: Lesions on nasal tip, left middle finger, right upper arm. 


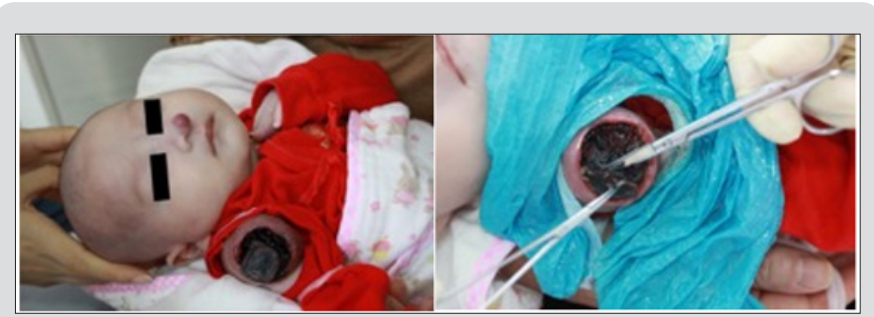

Figure 2: The ulceration on the right upper arm during the first course of oral prednisone and the debridement.

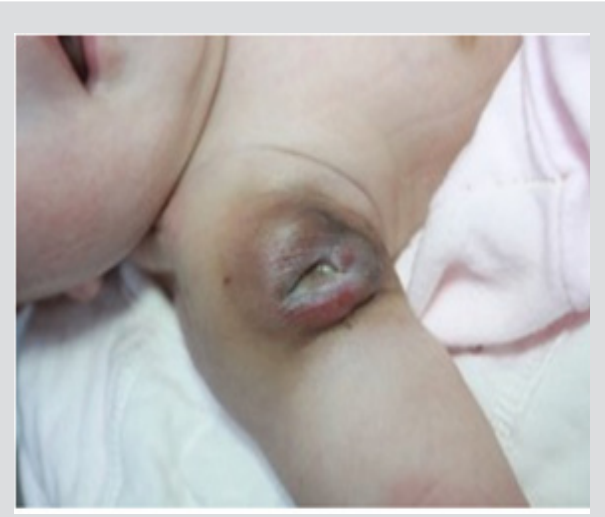

Figure 3: The right upper arm lesion after one course of oral prednisone, 3 sessions of debridement and LED treatment.

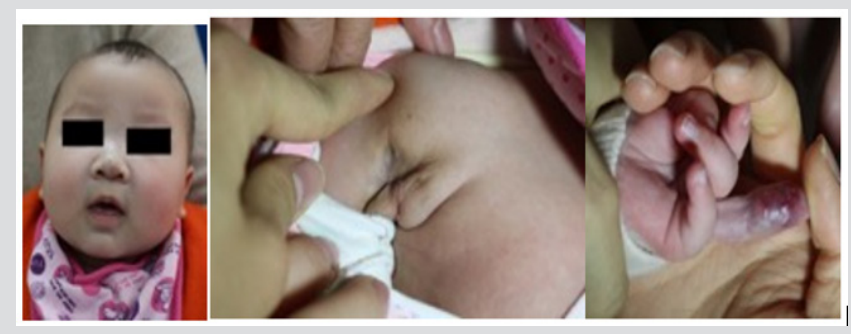

Figure 4: Three masses after three courses of oral prednisone.

\section{Discussion}

Hemangiomas are the most common benign soft tissue tumor of infancy and childhood, occurring in $12 \%$ of all infants and are found in greater frequency in girls, whites, premature infants, twins and are usually born to mothers of higher maternal age. In $80 \%$ of all cases, hemangiomas occur as single lesions. As the exact etiology remains unknown, some believe that hemangioma is not a true lesion, but a developmental anomaly or hamartoma instead [3]. The diagnosis of infantile hemangioma is straight forward from the history and clinical examination. Infantile hemangiomas arise during the first 8 weeks of life as an area of discoloration or telangiectasia (red spot in this case). The lesion exhibits a rapid proliferative phase and grows into a raised rubbery bright-red tumor [4]. This is followed by gradual involution and a spontaneous regression by the age of 5-9 years. 50\% of all hemangiomas will completely involute by the age of 5 years and $90 \%$ by the age of 9 years [4-7]. Meanwhile, $40 \%$ of involuted lesions, especially those ulcerated, may either show scaring, wrinkling, telangiectasia, or loose fibro-fatty tissue, which affects the appearance of patient [8].

The literature reveals infantile hemangioma is observed as a multiple lesion, located in head and neck region, extremities and internal organs. Hemangiomas occur most frequently in head and neck region (60\%), followed by the trunk (25\%) and the extremities (15\%), which are grouped into infantile hemangiomas and congenital hemangiomas [9]. Occurrence of IHs with their primary location on both head and neck region and extremities seem very rare. Clinical findings, history and USG result confirm us diagnose. Regarding treatment, we advise infantile hemangiomas with rapid proliferating and ulcerating risk require early intervention, especially combining with internal organ lesions. In the case discussed here, the treatment is comprised of oral prednisone. In the present case, the patient is undergoing follow-up and lesions are apparently involuting. Therefore, practitioners should notice that rapid treatment is essential for IH patients. Furthermore, to ignore the possibility of the intercurrent lesions interfering internal organs, which suggest the administration of systemic drugs, may bring out unexpected outcome.

\section{References}

1. Satish V, Bhat M, Maganur PC, Shah P, Biradar V (2014) Capillary Hemangioma in Maxillary Anterior Region: A Case Report. International journal of clinical pediatric dentistry 7(2): 144-147.

2. Fa C (1990) Glickman's clinical periodontology. Philadelphia: WB Saunders Co 335: 351.

3. Shafer WG, Hine MK, Levy BM (1963) A Textbook of Oral Pathology. In Shafer WG, Hine MK, Levy BM(eds.) (2 ${ }^{\text {nd }}$ Edn.), W B Saunders Company, Philadelphia.

4. Restrepo R, Palani R, Cervantes LF, Duarte AM, Amjad I, et al. (2011) Hemangiomas revisited: the useful, the unusual and the new. Part 1: overview and clinical and imaging characteristics. Pediatric radiology 41(7): 895-904.

5. Donnelly LF, Adams Dm Fau, Bisset GS (2000) Vascular malformations and hemangiomas: a practical approach in a multidisciplinary clinic. AJR Am J Roentgenol 174(3): 597-608.

6. Dadras SS, North Pe Fau, Bertoncini J, Mihm MC, Detmar M (2004) Infantile hemangiomas are arrested in an early developmental vascular differentiation state. Mod Pathol 17(9): 1068-1079.

7. Murthy J (2005) Vascular anomalies. Indian Journal of Plastic Surgery 38(1): 56-62.

8. Eivazi B, Ardelean M, Bäumler W, Berlien HP, Cremer H, et al. (2009) Update on hemangiomas and vascular malformations of the head and neck. European Archives of Oto-Rhino-Laryngology 266(2): 187-197.

9. Redondo P (2007) Vascular malformations (I). Concept, classification, pathogenesis and clinical features. Actas Dermo-Sifiliográficas (English Edition) 98(3): 141-158. 
ISSN: 2574-1241

DOI: 10.26717.BJSTR.2019.14.002497

Zhao Jianxin.Biomed J Sci \& Tech Res

CC (i) This work is licensed under Creative

Submission Link: https://biomedres.us/submit-manuscript.php

$\begin{array}{ll}\text { BIOMEDICAL } & \text { Assets of Publishing with us } \\ \text { RESEARCHES } & \text { - Global archiving of articles } \\ \text { - Immediate, unrestricted online access } \\ \text { ISSN:2574-1241 }\end{array}$

